Take a radius of a circle $A B$. Bisect it in $C$, and on $A C$ describe the equilateral triangle ACD. Mark off the chord AL equal to AC. With centre $L$ and radius $L D$ describe an arc cutting the circumference in $\mathrm{O}$. Then $\mathrm{CO}$ is approximately the side of the hendecagon. The angle subtended by $\mathrm{CO}$ at the centre is $32^{\circ} 44^{\prime} 29^{\prime \prime}$ instead of $32^{\circ} 43^{\prime} 38^{\prime \prime}$. It is to be noted that the angle which $A O$ subtends at $B$ is $21^{\circ} 12^{\prime} 42^{\prime \prime}$. The angle which the side of the regular 17-sided figure would subtend at $B$ is $21^{\circ} 10^{\prime} 35^{\prime \prime}$.

The calculation of this result suggested the following approximation. The length of the side of the 11-gon is equal to one-fifth the diagonal of the circumscribing square.

This gives an angle $32^{\circ} 51^{\prime} 35^{\prime \prime}$.

On the history and degree of certain geometrical approximations.

\title{
Part II.*
}

By A. J. Pressland, M.A.

$\$ 1$. Since the former paper on this subject was read, Prof. Cantor has published the second volume of his history of Mathematics. This has necessitated various additions to the paper, which can perhaps be best given as an appendix.

On page 413 Prof. Cantor says that the construction of Dürer's pentagon is found in a book called Geometria deutsch, which was lately discovered in the town library at Nürnberg, and gives 1487 as the upper limit to its date. The construction is said to be "mit unverrücktem Zirckel," the same expression that Schwenter applies to Dürer's solution.

Lionardo da Vinci (1452-1519) gave several methods of accurate and of approximate construction. Thus in fig. 18. the arc $b a=1 / 6$, the arc $b c=1 / 3$, the arc $c f=1 / 8$, and the arc $a f=$ $1 / 24$ of the circumference (p. 271).

Two constructions for the pentagon are also given by Lionardo. In fig. 19 the arcs are all of the same radius and the arc am is approximately $1 / 5$ of the circumference, the value on calculation being found to be $72^{\circ} 25^{\prime}$ (p. 272).

\footnotetext{
* This was read at the Sixth Meeting, 8th April, 1892.
} 
The second approximate solution consists in drawing an equilateral triangle $\mathrm{ABC}$, and the perpendicular $\mathrm{AD}$ on $\mathrm{BC}$. The side $\mathrm{AC}$ is assumed the chord of the regular pentagon in a circle radius DA. The angle so subtended is $70^{\circ} 31^{\prime} 42^{\prime \prime}$.

The following construction for the nonagon is due to Lionardo, (fig. 20). Let bna be an equilateral triangle; make $n g=a h$. Describe a circle with $g$ as centre, radius $g a$. As the angle $b g a=b k a=40^{\circ} 12^{\prime} 28^{\prime \prime}$, the line $b a$ is nearly the chord of the regular nonugon in this circle.

The expressions for the side of the 11-gon and 13-gon given by Schwenter are to be found in Dürer.

$\S 2$. The construction given by $A$ bû'l Wafâ for the regular heptagon is known as the Indian rule. It has been applied in different forms, as above to the 11-gon and 13-gon, to the construction of regular figures.

It admits, however, of various modifications.

(i) Considering it under the following aspect, " the $x^{\text {th }}$ part of the regular 8 -gon is the side of the regular $p$-gon in the same circle," the following results can be obtained :-

$$
\begin{aligned}
& s_{11}=9 / 32 \text { of the diameter gives an angle } 3^{\prime} 26^{\prime \prime} \text { too small. } \\
& s_{18}=1 / 4 \quad " \quad \text { gives an angle } 1^{\circ} 15^{\prime} \text { too large. }
\end{aligned}
$$

These are due to Dürer.

$$
\begin{gathered}
s_{17}=11 / 60 \text { of the diameter gives an angle } 20^{\circ} 7^{\prime} 40^{\prime \prime} \cdot 6 . \\
\begin{array}{c}
\text { instead of } 21^{\circ} 10^{\prime} 35^{\prime \prime} \\
\text { gives an angle } 19^{\circ} 56^{\prime} 54^{\prime \prime}
\end{array} \\
\begin{array}{c}
\text { instead of } 20^{\circ} \\
s_{18}=s_{3} / 5 \quad
\end{array} \\
s_{19}=1 / 6 \quad \text { of the diameter gives an angle } 19^{\circ} 11^{\prime} 17^{\prime \prime} \cdot 4 \\
\text { instead of } 18^{\circ} 56^{\prime} 41^{\prime \prime} .
\end{gathered}
$$

These are due to Schwenter.

Beyond these the following may be worth mention :-

$$
\begin{aligned}
& { }^{*} s_{29}=s_{3} / 8 \text { giving an angle } 12^{\circ} 25^{\prime} 45^{\prime \prime} \cdot 2 \\
& \text { instead of } 12^{\circ} 24^{\prime} 49^{\prime \prime} \cdot 6 \text {. } \\
& s_{31}=s_{4} / 7 \text { giving an angle } 11^{\circ} 34^{\prime} 43^{\prime \prime} \\
& \text { instead of } 11^{\circ} 36^{\prime} 46^{\prime \prime} \text {. } \\
& s_{5}=6 s_{32} \quad \text { giving an angle } 72^{\circ} \quad 2^{\prime} 42^{\prime \prime} \\
& \text { instead of } \quad 72^{\circ} 0^{\prime} 0^{\prime \prime} \text {. }
\end{aligned}
$$


This might be written $s_{5}=3 e_{10}$ but the approximation is not so near.

$$
s_{25}=s_{6} / 4 \begin{aligned}
& \text { giving an angle } 14^{\circ} 21^{\prime} 42^{\prime \prime} \\
& \text { instead of } 14^{\circ} 24^{\prime}
\end{aligned}
$$

(ii.) Considering the rule generalised thus, "The side of the n-gon minus the side of the s-gon is the side of the $r$-gon," the fol lowing results are found.

$$
\begin{aligned}
& s_{3}-s_{7}=s_{7} \\
& { }^{*} s_{10}-s_{17}=s_{25} \text { giving } 14^{\circ} 23^{\prime} 32^{\prime \prime} \cdot 4 \\
& \text { instead of } 14^{\circ} 24^{\prime} \quad 0 \text {. } \\
& s_{r}-s_{16}=s_{13} \text { giving } 27^{\circ} 38^{\prime} 6^{\prime \prime} \\
& \text { instead of } 27^{\circ} 41^{\prime} 32^{\prime \prime} \text {. } \\
& { }^{*} s_{24}+s_{34}=s_{14} \quad \text { giving } 25^{\circ} 42^{\prime} 54^{\prime \prime} \\
& \text { instead of } 25^{\circ} 42^{\prime} 51^{\prime \prime} \cdot 4 \text {. }
\end{aligned}
$$

Formed on the analogy of

$$
\begin{aligned}
& s_{5}^{2}=s_{6}^{2}+s_{10}^{2} \quad \text { (Euclid XIII. 10) } \\
& \text { and } \\
& s_{3}^{\prime}=s_{6}^{2}+s_{4}^{2} \\
& \text { are } \\
& { }^{*} s_{11}^{2}=s_{8}^{2}-s_{12}^{2} \text { giving } 32^{\circ} 44^{\prime} 44^{\prime \prime} \\
& \text { instead of } 32^{\circ} 43^{\prime} 38^{\prime \prime} \text {. } \\
& s_{13}^{2}=s_{12}^{2}-s_{32}^{2} \text { giving } 27^{\circ} 50^{\prime} 16^{\prime \prime} \\
& \text { instead of } 27^{\circ} 41^{\prime} 32^{\prime \prime} \text {. } \\
& s_{13}^{2}=s_{10}^{2}-s_{16}^{2} \text { giving } 27^{\circ} 44^{\prime} 6^{\prime \prime} \\
& \text { instead of } 27^{\circ} 41^{\prime} 32^{\prime \prime} \text {. }
\end{aligned}
$$

And the rougher approximation

$$
s_{11}^{2}-s_{13}^{2}=s_{21}^{2} \text {. }
$$

(iii.) Considering the rule generalised thus, "If $\mathrm{AB}$ be the side of the $n$-gon in a circle radius $\mathrm{CA}$, and $\mathrm{CA}$ be bisected in $\mathrm{D}$, then $\mathrm{BD}$ is the side of the regular s-gon," the following approximations may be obtained :-

$$
s_{6} \text { gives } s_{7}
$$

$s_{8}$ gives for $2 s_{17}$ the angle $21^{\circ} 13^{\prime} 46^{\prime \prime}$ instead of $21^{\circ} 10^{\prime} 35^{\prime \prime}$.

$s_{10}$ gives for $2 s_{19}$ the angle $19^{\circ} \quad 6^{\prime} 46^{\prime \prime}$ instead of $18^{\circ} 56^{\prime} 51^{\prime \prime}$. 


$$
\begin{array}{cllll}
s_{12} \text { gives for } s_{10} & \text { the angle } 36^{\circ} & 6^{\prime} & 8^{\prime \prime} \\
& \text { instead of } 36^{\circ} & 0^{\prime} & 0^{\prime \prime} . \\
s_{15} \text { gives for } 2 s_{5} & \text { the angle } 70^{\circ} & 54^{\prime} & 26^{\prime \prime} \\
& \text { instead of } 72^{\circ} & 0^{\prime} & 0^{\prime \prime} . \\
& s_{17} \text { gives for } s_{11} & \text { the angle } 32^{\circ} & 43^{\prime} & 44^{\prime \prime} \cdot 8 \\
& \text { instead of } 32^{\circ} & 43^{\prime} & 38^{\prime \prime} \cdot 2,
\end{array}
$$

an approximation first suggested by Le Clerc's construction for $\boldsymbol{s}_{11}$.

$$
\begin{gathered}
s_{39} \text { gives for } s_{12} \text { the angle } 30^{\circ} 12^{\prime} 48^{\prime \prime} \\
\text { instead of } 30^{\circ} 0^{\prime} \quad 0^{\prime \prime}
\end{gathered}
$$

suggesting an approximation to $8_{39}$.

It is to be noted that this variation of the Indian rule is used in the Almagest construction (accurate) of the regular pentagon by Ptolemy.

(iv.) The following construction, though not an adaptation of the Indian rule, was suggested by it (fig. 21).

Let $\mathrm{BE}$ be the side of the $n$.gon in a circle radius OB. Bisect $O B$ at $D$. Join ED and draw OF perpendicular to it. The locus of $F$ is a circle with $O D$ diameter. The angle $D O F$ may give approximations to the side of the regular polygons.

Thus

$$
\begin{aligned}
& \text { with } s_{8} \text { the angle } \mathrm{DOF}=0^{\circ} \text {. } \\
& \text { with } s_{7} \text { the angle } \mathrm{DOF}=8^{\circ} 58^{\prime} \text {, giving an approximation to } s_{40} \\
& \text { with } s_{8} \text { the angle }=16^{\circ} 19^{\prime} 30^{\prime \prime} \quad " \quad, \quad \text { to } s_{11} \\
& \text { "with } 8_{9} \text { the angle }=22^{\circ} 29^{\prime} \quad " \quad " \quad \text { to } s_{16} \\
& \text { with } s_{10} \text { the angle }=27^{\circ} 44^{\prime} \quad " \quad, \quad \text { to } s_{18} \text {. }
\end{aligned}
$$

By reversing the construction of the fourth of these an extremely near approximation to $s_{9}$ is obtained, the angle being $39^{\circ} 59^{\prime} 15^{\prime \prime} \cdot 5$ instead of $40^{\circ}$. result.

§3. From the following construction certain approximations

Take a radius $A B$ and draw the tangent at $B$. Take a point $C$ on the circle and draw $C E$ perpendicular to the tangent at $B$. Then $\sin \mathrm{CAB}=\tan \mathrm{EAB}$. Calling $\mathrm{CAB} \theta$, and $\mathrm{EAB} \phi$, this gives :

$$
\theta=40^{\circ} ; \phi=32^{\circ} 43^{\prime} 56^{\prime \prime} \cdot 7 \text {. }
$$

-From which $8_{9}$ gives $8_{11}$. 
With the previous approximation to $s_{9}$ the angle obtained is $32^{\circ} 43^{\prime} 32^{\prime \prime} \cdot 5$. The true angle is $32^{\circ} 43^{\prime} 38^{\prime \prime} \cdot 1$.

The equation $\frac{1}{2} \sin \theta=\tan \psi$ gives :

$$
\theta=40^{\circ} ; \psi=18^{\circ} 50^{\prime} 58^{\prime \prime} \cdot 5 \text {, thus approximating to } s_{18}
$$

With $\theta=20^{\circ} ; \phi=18^{\circ} 52^{\prime} 54^{\prime \prime} \cdot 1$, again approximating to $s_{10}$ where the angle is $18^{\circ} 56^{\prime} 41^{\prime \prime}$.

With $\theta=\frac{360^{\circ}}{19} ; \phi=17^{\circ} 59^{\prime} 19^{\prime \prime}$. From which $s_{19}$ gives $8_{20}$

As $8_{20}$ can be found exactly, this construction can be reversed.

With $\theta=18^{\circ} ; \phi=17^{\circ} 10^{\prime} 19^{\prime \prime} \cdot 3$. From which $s_{20}$ gives $8_{21}$ the correct angle for $8_{21}$ being $17^{\circ} 8^{\prime} 34^{\prime \prime}$.

\$4. In fig. 22, AB, CD are two diameters of a circle perpendicular to each other ; $\mathrm{AE}, \mathrm{BF}$, tangents at $\mathrm{A}, \mathrm{B}$, are equal to four times the radius and the radius respectively. Join EF cutting the circle at $\mathbf{M}, \mathbf{N}$; and join $\mathbf{A M}, \mathbf{A N}$, cutting $\mathrm{CD}$ at $m, n$. Through $m, n$ draw parallels to $A B$, namely $G H, I K$. The pentagon OIHGK is regular. M. Henri Barral, in Nouvelles Annales, XI. 388-390 (1852).

The construction above is given by Herr Staudt without proof in Crelle XXIV. (1842).

Terquem in a note says, "The construction of Herr Staudt is remarkable because it indicates an analogous construction for the division of the circumference into 17 equal parts." See also Nouvelles Annales, XVI. 310 (1857).

Among the calculations made for this paper the following occurred :-

$$
61 \cdot 5-10 \sqrt{5}=39 \cdot 139320225,
$$

a near approximation to the length $39 \cdot 13929 \ldots$ inches of the seconds pendulum in London.

On Electrolysis.

By Professor Morrison. 